\section{Dentro do Segredo: Representações da Coreia da Norte na narrativa de viagens de José Luís Peixoto}

\author{
Inside the Secret: North Korean representations in José Luís Peixoto's travel \\ narrative
}

\author{
Ana Margarida Fonseca \\ Instituto Politécnico da Guarda, ILCML-FLUP, CEC-FLUL \\ anafonseca@ipg.pt
}

\begin{abstract}
Resumo
Dentro do Segredo - Uma viagem na Coreia do Norte representa a estreia de José Luís Peixoto na literatura de viagens, através de uma incursão na Coreia do Norte, o país mais fechado do mundo. Cruzando o relato de viagens clássico com uma profunda introspeção interior, para além de reflexões acerca da realidade política, social e histórica do território, o autor apresenta uma visão subjetiva do país, onde realidade e simulacro se cruzam e a verdade permanece apenas uma ilusão. O leitor depara-se, assim, com um paradoxo: que turismo possível num espaço fortemente controlado e onde a liberdade do visitante é à partida coartada? Propomo-nos, assim, refletir sobre as condições da escrita da viagem nesta narrativa de José Luís Peixoto, tendo presente quer a possibilidade do turismo literário, alimentado pela escrita introspetiva, quer a tensão entre o real percebido e o real simulado.
\end{abstract}

Palavras-chave: José Luís Peixoto; Coreia do Norte; turismo; narrativa de viagens; real; simulacro.

\begin{abstract}
Dentro do Segredo - Uma viagem na Coreia do Norte (Inside the secret - A journey in North Korea) represents José Luís Peixoto's debut in travel literature, through an incursion into North Korea, the most closed country in the world. Blending the classic travel narrative with a deep inner introspection, as well as reflections on the political, social and historical reality of the territory, the author presents a subjective vision of the country, where reality and simulacrum intersect and the truth remains only an illusion. The reader is thus faced with a paradox: what kind of tourism is possible in a strongly controlled space and where the freedom of the traveller is curtailed? We thus propose to reflect on the conditions of the writing of the journey in this narrative by José Luís Peixoto, keeping in mind both the possibility of literary tourism, nurtured by the introspective writing, and the tension between perceived reality and simulated reality.
\end{abstract}

Keywords: José Luís Peixoto; North Korea; tourism; travel narrative; real; simulacrum.

Dos Algarves: A Multidisciplinary e-Journal, 37 -2020.

ISBN 2182-5580 ๑ ESGHT - University of the Algarve, Portugal.

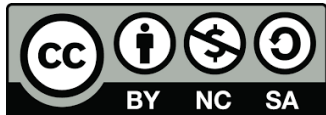




\section{Introdução}

Os segredos estão dentro de nós. Como tudo o que sabemos, também os segredos nos constituem. Quando os seguramos, quando somos mais fortes e os contemos, alastram-se em nós. Desde dentro, chegam à nossa pele. Depois, avançam até sermos capazes de os distinguir à nossa volta. E, no silêncio, somos capazes de os reconhecer. Então, nesse momento, já não são apenas os segredos que estão dentro de nós, somos também nós que estamos dentro dos segredos. (Peixoto, 2012: 136)

Em 2012, o escritor José Luís Peixoto publicou Dentro do Segredo, o relato de uma viagem à Coreia do Norte feita em abril desse mesmo ano, integrado num pequeno grupo de visitantes ocidentais. O título da obra alude a múltiplos segredos: o segredo da sua própria viagem, pois apenas as irmãs e a mãe conhecem o seu paradeiro durante aquelas duas semanas; o segredo que o país constitui para os estrangeiros; o segredo causado pela incomunicabilidade praticamente total em que mergulha. Em pouco mais de 400 páginas, o autor leva-nos pelo interior do país mais isolado do mundo, cruzando o relato de viagens clássico com uma profunda introspeção pelas emoções vividas nesse período, para além de reflexões acerca da realidade política, social e histórica do território.

Proposta como narrativa de viagens, Dentro do Segredo distingue-se, desde logo, pelo facto de contrariar alguns dos pressupostos do subgénero em termos das condições de realização da própria viagem. Na verdade, em 2012 como hoje, não são permitidos viajantes independentes na Coreia do Norte: todos os visitantes têm de integrar um grupo préorganizado, com guias designados pelo Estado, e obedecer a um itinerário e a horários rigidamente estabelecidos. Tudo está pré-definido: sítios a visitar, hotéis, restaurantes, aproximando-se por isso mais da clássica excursão própria do turismo massificado do que da viagem, entendida como exploração subjetiva do território do outro. Em contrapartida, o reduzido número de visitantes, a limitação de registos fotográficos e a escassez de conforto nas poucas estruturas hoteleiras disponíveis contrariam essa mesma lógica do turismo de massas, afastando a experiência do que seria normal encontrar num tour em qualquer parte do mundo.

O leitor depara-se, assim, desde as primeiras páginas com um paradoxo: que turismo possível num espaço fortemente controlado e sob condições tão distantes dos padrões ocidentais? E como experienciar uma viagem sem a margem de imprevisto e liberdade que a mesma supõe? Refletir sobre este paradoxo e sobre as condições da escrita da viagem na narrativa de José Luís Peixoto constitui um propósito central neste texto, ao qual acrescentamos a importância de pensar o turismo literário e o turismo na literatura sob condições de exceção como aquelas experienciadas na Coreia do Norte.

Para tal, procuraremos enquadrar a atividade turística na Coreia do Norte recorrendo, sobretudo, à análise da informação contida em meios digitais e editoriais amplamente difundidos no Ocidente. Perante a escassez de investigação especializada na área dos estudos de turismo e especificamente orientados para este território, serão ainda discutidos alguns textos produzidos em anos recentes, especialmente pertinentes para a abordagem da obra de José Luís Peixoto. 


\section{Coreia do Norte: 0 turismo (im)possível}

Fechada ao turismo durante décadas, a Coreia do Norte tem, desde os finais dos anos oitenta do século $X X$, permitido a entrada de visitantes, sem que tal signifique um abrandamento significativo das políticas de controlo. Uma pesquisa pelo Tripadvisor, porventura a mais popular plataforma de turismo e viagens do mundo, mostra conteúdos aparentemente idênticos a qualquer outro destino: um ranking de hotéis e restaurantes, com as respetivas avaliações dos utilizadores; uma lista de atrações, contemplando monumentos, museus, natureza e outros espaços de entretenimento; locais para fazer compras. A aparente normalidade não resiste a uma análise mais atenta, que nos revela a impossibilidade de fazer reservas diretas de hotéis ou de automóveis, assim como o escasso número quer de restaurantes e hotéis quer de avaliações feitas aos mesmos. Apenas o hotel Yangaddko e o hotel Koryo, em Pyongyang, se destacam pelo elevado número de avaliações (mais de 500 para o primeiro e mais de 200 para o segundo), pelo facto de serem os hotéis destinados aos visitantes estrangeiros que chegam nas excursões organizadas.

A apetência dos ocidentais pela Coreia do Norte é igualmente denunciada pela disponibilização de guias e dicas de viagem por parte de numerosos sites e empresas da área do turismo. Durante muitos anos, o único guia impresso sobre a Coreia do Norte era da autoria de Robert Willoughby, publicado por Bradt Travel Guides, a que se juntou em 2019 o Rocketbone's Guide to North Korea, escrito por J. R. JaBone. Editoras mundialmente conhecidas como a Lonely Planet ou a Rough Guides incluem, em volumes impressos sob a designação genérica de "Coreia", capítulos dedicados ao país e muitos sites² disponibilizam igualmente páginas de informação a potenciais visitantes, com informação semelhante à que se encontra para outras regiões do mundo, mas incluindo as necessárias advertências acerca da obrigatoriedade de viagens organizadas, itens proibidos, comportamentos a evitar ou a seguir. Outro sinal da crescente importância do turismo na Coreia do Norte é a criação de um site oficial ${ }^{3}$ em coreano e em inglês, assim como a diversificação de agências com permissão para levar turistas para o território.

Existe, assim, uma aparente normalização do turismo, que contrasta com a manutenção de exigências em tudo contraditórias com a conceção ocidental da atividade e com as reservas colocadas por parte das autoridades de muitos países ocidentais: tal como em 2012, por altura da viagem de José Luís Peixoto, mantém-se a proibição de os turistas andarem sozinhos ou de transportarem consigo livros e guias sobre a Coreia ou ainda tecnologia GPS; a impossibilidade de aceder à rede de internet ou ao correio eletrónico; a retenção do passaporte por parte dos guias; as limitações nas fotografias e o controlo das mesmas à

\footnotetext{
${ }^{1}$ Em ambos os casos, a Coreia do Norte ocupa os capítulos finais de volumes com cerca de 400 páginas, representando esses capítulos apenas cerca de vinte páginas do total.

${ }^{2}$ A multiplicação destes "guias virtuais" é imensa, pelo que mencionamos apenas alguns exemplos em língua inglesa: https://www.worldtravelguide.net/guides/asia/north-korea/, https://www.worldnomads.com/travel-safety/eastern-asia/north-korea/north-korea-travel-tips, https://www.nationalgeographic.com/travel/destinations/asia/north-korea/, https://amuse.vice.com/en_us/article/439m dm/north-korea-travel. Em português encontram-se sobretudo referências genéricas em sites de turismo e páginas de bloggers, mais específicas e detalhadas nos raros casos em que efetivamente os autores viajaram para lá, como é o caso de João Leitão: https://www.joaoleitao.com/viagens/visitar-coreia-do-norte/

3 http://tourismdprk.gov.kp/. Observe-se que o site está frequentemente inacessível.
} 
saída. Alguns pequenos sinais de abertura, como a possibilidade de manter o telemóvel desde que seja usado um cartão SIM local, a existência de alguns canais de televisão estrangeiros no hotel ou o aumento de agências de viagens autorizadas, não alteram, pois, o regime de exceção aplicado aos estrangeiros e o controlo estatal daquilo a que o turista tem acesso.

Se uma viagem para a Coreia do Norte implica tantas limitações, é dispendiosa e potencialmente arriscada, o que atrai então os milhares de turistas que anualmente procuram o país?

Num dos raros estudos sobre o turismo neste território, Dorina Maria Buda e David Shim, em "Desiring the dark: 'a taste for the unusual' in North Korean tourism?" apresentam uma análise baseada em relatos de turistas ocidentais publicados na imprensa. Os autores começam por observar que os turistas ocidentais não são repelidos pelo surgimento de más notícias a respeito dos territórios a visitar, pelo contrário, são incentivados por elas. Assim, o turismo para "zonas de perigo" (danger zone tourism) 4 resulta da ativação de distintos mecanismos de desejo, desde logo o desejo de novidade (desire for novelty), ou seja, a atração pelo incomum, pelo não familiar, intensificado pela restrição de movimentos experienciada no país. O desejo de que os outros reconheçam o seu próprio desejo (desire for recognition), associado ao prestígio que tal viagem representa, constitui, segundo os autores, outra das motivações dos turistas, pois quem viaja sente que está a desafiar o proibido e a mostrar aos outros uma realidade interdita. Os relatos de viagem manifestam, neste enquadramento, uma exposição da própria audácia e alimentam por sua vez o desejo dos outros. Por fim, os turistas mobilizam ainda o desejo de fantasia (desire for fantasy) na invocação de imaginação de atividades e lugares misteriosos e potencialmente perigosos. De facto, na Coreia do Norte os turistas permanecem num estado permanente de corroboração entre a fantasia e a realidade observada, confrontando o que é "encenado" com vislumbres do que pode ser o "autêntico".

Assim, a radicalidade do outro e o mistério contribuem decisivamente para o poder de atração de tal viagem: "For many, not only in the 'west', but also in the 'rest', North Korea seems mysterious, isolated and unknowable, something that makes it a 'global other' of the contemporary age. In this way, this (imagined) mysteriousness contributes to enhancing desire towards North Korea." (Buda \& Shim, 2015: 4).

John Connell, em reação a este ensaio, contesta a ideia de que o turismo na Coreia do Norte seja motivado pela procura da "escuridão" e pela fantasia, considerando que é precisamente o seu oposto - a "normalidade", a realidade prosaica - que os visitantes demandam: "The search for an everyday moral order does not imply dark tourism" (2017: 358). Na sua perspetiva, os turistas pretendem confrontar as imagens tendenciosas e unilaterais veiculadas pelos media, questionando a negatividade presente na visão hegemónica do exterior, bem como fugir o mais possível da "bolha" coreografada e controlada que é mostrada aos estrangeiros. O que os move é, pois, na maioria dos casos, a obtenção de um maior conhecimento acerca do país e uma aproximação empática aos habitantes, o que os afasta do dark tourism: "Tourism in North Korea is no resort holiday, or

\footnotetext{
${ }^{4}$ Buda e Shim inserem esta forma de turismo na categoria mais ampla de dark tourism, definido como o turismo para locais historicamente associados à morte, à tragédia ou ao macabro.
} 
flight of fancy and fantasy, but a serious undertaking, a form of moral political tourism, in a mode and place for learning" (Connell, 2017: 361).

Apesar do distanciamento de posições, julgamos que ambas se complementam na compreensão das motivações do turismo norte-coreano. Se é certo, como afirma Connell, que muitos visitantes são movidos pelo desejo de aproximação ao outro e ultrapassagem dos estereótipos veiculados nos países ocidentais, será difícil negar que essa aproximação é, em grande parte, impulsionada pelo apelo do incomum e do insólito. O turismo moral que, na visão do autor, caracteriza os viajantes resulta, a nosso ver, de um desejo muito mais poderoso do que aquele que é exercido por territórios mais abertos e acessíveis - não porque exista uma superioridade moral por parte dos próprios turistas, mas porque estes, como justamente assinalam quer Connell quer Buda e Shim, procuram as "falhas" na encenação, os vestígios de autenticidade numa realidade que sabem à partida estar-Ihes vedada. Por outras palavras, dificilmente o desejo de novidade e a fantasia não estarão, em grande medida, presentes nesse impulso para uma viagem que se sabe à partida contrariar os padrões de conforto e lazer associados ao turismo de massas, ainda que o retorno seja moralmente satisfatório.

José Luís Peixoto, no segundo capítulo de Dentro do Segredo, descreve as circunstâncias em que surgiu a ideia obsessiva de viajar para a Coreia do Norte: nos primeiros meses de 2011, em Los Angeles, o autor conheceu Chiwan, filho de pais norte-coreanos que tinham fugido do país, e com ele manteve um contacto regular. Foi nessa altura, a viver num bairro de imigrantes coreanos, que tomou a decisão, admitindo que há muito tempo "sentia curiosidade por sociedades fechadas e sistemas políticos totalitários", na perspetiva de "tentar perceber o quotidiano de quem vive nessas sociedades" (Peixoto, 2012: 23).

O perfil deste específico viajante parece ajustar-se àquele traçado por Connell: "Tourism to North Korea thus constitutes a form of serious political tourism where tourists seek to develop a moral perspective on a place that has hitherto eluded their understanding." (2017: 359-360). As motivações do autor nem para o próprio são inequívocas, havendo uma componente de ininteligibilidade que é assumida: "Para mim, talvez a decisão de visitar a Coreia do Norte tenha nascido do desejo de estar num lugar onde nenhuma pessoa tivesse a minha aparência. Ou talvez não." (Peixoto, 2012: 22). A radicalidade da diferença do outro constitui, sem dúvida, um fator mobilizador, se bem que apenas se torne consciente durante a própria viagem que a grande razão são as pessoas, na sua humanidade mais despida de ideias pré-concebidas. Numa paisagem rural, à margem do roteiro oficial definido pelos guias, rodeado pelo silêncio de tempos pré-modernos, o autor-viajante observa as pessoas na simplicidade das atividades diárias e é aí que compreende finalmente a demanda por um território tão longínquo (Peixoto, 2012: 22).

Quanto ao restante grupo, José Luís Peixoto apenas o descreve brevemente no início da viagem, salientando a diversidade das origens, a prevalência do sexo masculino e - mais importante - o facto de não partirem para a visita de forma ingénua:

Éramos vinte e poucos. Afinal, não pareciam muito diferentes de mim: eram quase todos homens, apenas três mulheres, e tinham mais ou menos a mesma idade, um pouco mais ou um pouco menos de trinta e sete anos. Eram de várias partes do mundo, de Inglaterra, da Austrália, da Nova Zelândia, três dos Estados Unidos e alguns, como eu, vinham sozinhos de diversos países. Aparentemente, eram grandes conhecedores da Coreia do Norte. (Peixoto, 2012: 35) 
O conhecimento dos turistas é idêntico ao conhecimento do autor: assente em livros e reportagens, é também ela uma perspetiva mediada pela narrativa alheia, ainda que mais sofisticada do que a do turista médio. Neste sentido, todos eles partem para a visita com conhecimentos pré-concebidos que, de uma forma ou outra, esperam confirmar, ainda que a margem de surpresa e imprevisto, embora reduzida, se faça anunciar a espaços. ${ }^{5}$

\section{Literatura de viagens e turismo literário}

José Luís Peixoto escreve e publica Dentro do Segredo. Uma viagem na Coreia do Norte no mesmo ano em que a visita, explicitando nas últimas páginas da obra que a mesma começou a ser escrita ainda na China e continuou após o regresso, impulsionada ainda por uma outra viagem, desta feita aos Estados Unidos com a mãe e os filhos. Ainda que tivesse sido forçado a assinar uma declaração em que se comprometia a não escrever nada sobre o que iria ver, o autor suspeitava, mesmo antes de iniciar a viagem, que dificilmente tal aconteceria. Sendo o primeiro a fazê-lo no conjunto da literatura escrita em português, o autor junta-se a uma pequena galeria de narrativas de viagem centradas na Coreia do Norte, ${ }^{6}$ a maioria em língua inglesa.

Entendida na contemporaneidade de uma forma mais introspetiva e autorreflexiva, a narrativa de viagens constitui um modo de aproximação à alteridade e um meio de redefinição do conhecimento do eu. A voz do autor, que está ausente do guia de viagens, é fundamental nesta tipologia textual, que evoluiu de uma pseudo-objetividade e pretensão didática para uma auto-exploração quer do espaço físico quer interior. O leitor faz momentaneamente parte dos conflitos internos e desafios emocionais do escritor-viajante, recorrendo à literatura de viagem em procura de um conhecimento "de dentro", diferenciado do turismo de massas (Robinson, 2004: 309-310).

Casey Blanton (2002) salienta igualmente esta alteração no género, apontando para um novo paradigma em que o viajante se aproxima do outro com menos bagagem cultural e menos certezas, determinado a conhecer-se melhor e a redefinir a sua relação com os que Ihe são estranhos:

\footnotetext{
${ }^{5}$ Um desses momentos em que é assumida a contradição com as expectativas acontece aquando da subida à colina Moran, no parque Morabong, onde o grupo de turistas encontra numerosos norte-coreanos num momento de lazer, a dançar animadamente. A interação dos locais com os estrangeiros colide com tudo o que tinham aprendido sobre o país: "Os estrangeiros que viajavam comigo também estavam lá no meio, a dançar com eles. Os mais tímidos, encostados aos troncos das árvores, recebiam convites sucessivos de coreanos que se aproximavam a sorrir, lhes esticavam a mão e os tentavam levar para o meio da dança. (...) Os estrangeiros pareciam surpreendidos. Muitos provavelmente tinham lido os mesmos livros que eu. Uma boa parte desses livros assegurava que os norte-coreanos tinham ordens expressas para não manter qualquer espécie de contacto com estrangeiros. (...) Nesse ponto, aquilo que os livros diziam não correspondia à realidade. Se alguma vez tinha sido assim, deixara de o ser. Estava rodeado por essa evidência." (Peixoto, 2012: 63-64).

${ }^{6}$ Se é certo que a maioria dos relatos de viagem, mesmo alguns consideravelmente extensos, se encontram sobretudo publicados em páginas de internet e blogues de viagem, é possível encontrar alguns volumes em livro, dentro da categoria de narrativa de viagens. Entre outros, considerem-se os seguintes títulos (por ordem cronológica de edição): Au pays du grand mensonge de Philippe Grangereau (2000), Le Dernier Paradis: Voyage en Corée du Nord de Nicolas Righetti (2003), Cerrado 24 horas: Crónica de un viaje a Corea del Norte de Beatriz Martínez Pitarch (2012), My Holiday in North Korea: The Funniest/Worst Place on Earth de Wendy E. Simmons (2015), Corea del Nord: Viaggio nel paese-bunker de Federico Giuliani (2018), En Corea del Norte: Viaje a la última dinastía comunista de Florencia Grieco (2018), North Korea Journal de Michael Palin (2019), Traveling Through North Korea: Adventures in the Hermit Kingdom de Stephen Harris (2019).
} 
Stylistically these new books tend to 'fall apart'. Freed from strictly chronological, fact driven narratives, nearly all contemporary travel writers include their own dreams and memories of childhood as well as chunks of historical data or synopses of other travel books. Self-reflexivity and instability, both as theme and style, offer the writer a way to show the effects of his or her own presence in a foreign country and to expose the arbitrariness of truth and the absence of norms. (Blanton, 2002: 27)

À parte algumas crónicas previamente publicadas na revista Volta ao Mundo, Dentro do Segredo representa a primeira incursão do autor no subgénero da literatura de viagens, prosseguida em O Caminho Imperfeito (2017). A remissão para aspetos da vida pessoal do autor, como a referência às relações familiares, ao afeto pelos filhos, ou aos compromissos profissionais perpassa por toda a obra, que se assume, desassombradamente, como não ficcional.7 Tal não contraria, antes reforça, o fértil hibridismo entre a escrita ficcional e a escrita não ficcional, uma vez que as particularidades estilísticas se prolongam e são reconhecíveis na narrativa de viagens: ${ }^{8}$ Se "[v]iajar é interpretar" (Peixoto, 2012: 61) e a imparcialidade constitui uma ilusão, no contexto da Coreia da Norte esse reconhecimento é ainda mais necessário. Ninguém tem toda a informação "O secretismo e as enormes idiossincrasias desta sociedade fazem com que o olhar do viajante seja muito conduzido por aquilo que leu em livros antes de chegar. Ao fazê-lo, parece-me, acaba por procurar na paisagem exemplos do que já sabe. Por isso, a interpretação que cada um faz depende dos livros que leu." (Peixoto, 2012: 62).

Deste modo, o visitante nunca parte de um "grau zero" de conhecimento; as narrativas que leu condicionam a imaginação; e também esta narrativa será apenas mais uma interpretação, cabendo ao autor a única responsabilidade possível: "ser fiel à verdade que conheço e em que acredito" (Peixoto, 2012: 62).

A excecionalidade do contexto norte-coreano faz-se sentir também neste plano, pois como justamente aponta Blanton (2002: 29), "by the late twentieth century, the role of travel books have changed. They are no longer our only source for the exotic; we can see that at our own gates and in our living rooms. The new travel books are not our guides for to places remote; nowhere is remote anymore.". Ora, como salientado previamente, neste caso é mesmo disso que se trata - ter acesso, pelos livros, ao que é remoto e desconhecido. Último reduto de uma realidade exótica e inacessível (mesmo com a abertura cautelosa ao turista), a Coreia do Norte faz-se conhecer sobretudo pelas narrativas que viajantes e turistas dela fazem e daí a proliferação, que abordámos no ponto anterior, de relatos mais ou menos sofisticados acerca do país por parte dos visitantes ocidentais. Assim, a narrativa de viagens desenvolve-se no paradoxo entre a contemporaneidade de um subgénero que se reinventa e a função mais antiga de permitir o acesso a uma realidade duplamente longínqua - pela geografia e pelo regime totalitário que retém o país no isolamento. Profundamente moderna no estilo e na perspetiva, a narrativa de José Luís Peixoto não pode deixar de refletir o facto de que o leitor encontra nestas páginas um espaço incomum, do qual tem poucas ou nenhumas referências visuais e sobre o qual subsistem mitos e preconceitos.

\footnotetext{
7 José Luís Peixoto, de forma algo provocatória, faz questão de avisar o leitor que, por razões burocráticas, relacionadas com a proibição de escrever sobre a viagem, pode ser obrigado a declarar a ficcionalidade da obra, algo a que o leitor não deve dar crédito: "Se essas linhas existirem serão elas próprias a única ficção presente neste livro. Garanto." (Peixoto, 2012: 36).

${ }^{8}$ A este propósito, cf. o ensaio de Vânia Rego (2017).
} 
Outro paradoxo incontornável diz respeito às específicas circunstâncias em que não só José Luís Peixoto, mas todos os autores de narrativas de viagens acerca da Coreia do Norte, visitam o país. Uma vez que são proibidas visitas independentes, a única opção do viajante é integrar uma excursão pré-definida, comercializada por uma das agências autorizadas, onde todo o itinerário está rigidamente determinado e o contacto com os locais é fortemente limitado. Não há lugar para o imprevisto, o desconhecido, a experiência solitária ou a imersão na cultura do outro - traços fundamentais do viajante. Em contrapartida, nenhum estrangeiro parte para a Coreia do Norte na expectativa de ter a experiência típica do turismo de massas: hotéis de luxo, comida gourmet, compras, um período de descanso e lazer sem outras preocupações, ainda que haja um esforço por parte das autoridades oficiais em oferecer um simulacro dessa experiência. ${ }^{9}$ Deste modo, a realidade norte-coreana desafia a dicotomia que geralmente se estabelece entre turista e viajante, baralhando as sistematizações que atribuem ao primeiro um estatuto de superficialidade e comodismo e ao segundo um propósito de conhecimento do outro e questionamento dos lugares comuns. ${ }^{10}$

Ainda que os conceitos se encontrem interligados, "o turismo não se esgota na viagem" (Quinteiro \& Baleiro, 2017: 18), distinguindo-se o primeiro pela vontade de sair dos cenários habituais e procurar experiências de prazer. Já a viagem engloba deslocações de todo o tipo, com as mais variadas finalidades, enquanto o turismo está associado à ideia de férias e denota um movimento temporário para destinos fora do ambiente e das atividades habituais (Medlik, 2003: vii). Inserindo-se nesta definição genérica, o turismo de massas diz respeito especificamente ao fenómeno de grandes movimentos de turistas que compram um "pacote" estandardizado de férias. Aponta-se como principal motivação do turismo massificado o desejo de escape ao tédio do quotidiano para um mundo de sonho, conduzindo ao consumo da inautenticidade e da trivialidade (Prentice, 2004: 264).

Obrigado ao consumo de um "pacote" apenas na aparência igual a tantos outros pelo mundo fora, de entre o elenco oferecido por uma agência com escritório em Pequim, José Luís Peixoto escolhe a Kim Il-sung 10oth birthday Ultimate Mega Tour (Ultimate Option), um itinerário excecionalmente longo, de quinze dias, coincidente com as comemorações do centésimo aniversário do líder já falecido Kim Il-Sung. A reunião antes da partida para a Coreia do Norte apenas na aparência se assemelhava a qualquer outro encontro preparatório de uma excursão: as informações prestadas introduzem os turistas-viajantes nas peculiaridades de uma visita onde os participantes não podiam levar certos livros ou telemóvel, tirar fotos e filmar livremente, bem como afastar-se dos guias; eram também obrigados a nunca cortar partes do corpo nas fotografias das estátuas dos líderes, guardar o jornal distribuído no avião, para além de outras regras profusamente explicadas pelos guias norte-coreanos que os acompanharão. O viajante que o autor realmente é deixa-se camuflar por esta pele superficial de turista num circuito com nome ridiculamente pomposo; será por entre as margens e os espaços em branco da rigidez oficial que se podem entretecer os momentos de fruição individual e de descoberta, como aquele em que o autor se mistura com os coreanos que assistem ao fogo-de-artifício no rio Taedong, no aniversário do líder, e passa despercebido no meio deles (Peixoto, 2012: 227-228).

\footnotetext{
9 Explicitaremos alguns exemplos deste simulacro em Dentro do Segredo no ponto seguinte.

10 Para uma sistematização das diferenças entre turista e viajante, veja-se Sílvia Quinteiro e Rita Baleiro (2017: 8496).
} 
Por fim, importa ainda chamar a atenção para a relevância do que pode ser entendido como o desenvolvimento de formas de turismo cultural e literário na Coreia do Norte. Definido de forma simples como "um nicho do turismo cultural que tem a especificidade de implicar a deslocação a lugares relacionados com a literatura" (Baleiro \& Quinteiro, 2017: 3334), no turismo literário "é o texto que dá origem à viagem e não a viagem que dá origem a um texto" (Baleiro \& Quinteiro, 2017: 36). Anteriormente referimos a importância das narrativas de viagem acerca da Coreia do Norte, pelo facto de constituírem praticamente a única fonte de informação para os potenciais visitantes ocidentais e por constituírem mesmo, em muitos casos, uma motivação determinante para a decisão de visitar o país. O objetivo é, neste caso, conhecer os lugares das obras, reconstituir percursos abertos pelo olhar de outros que os precederam e que fazem testemunho da riqueza cultural e ontológica de uma viagem radicalmente distinta de qualquer outra.

Na sequência do sucesso da obra Dentro do Segredo, a agência Pinto Lopes Viagens convidou José Luís Peixoto, logo após a publicação do livro, "a construir um itinerário que passasse por alguns dos pontos que tinha descrito, e a acompanhar quem se inscrevesse nessa aventura" (Peixoto, 2015). Após uma reflexão de alguns meses, durante a qual teve oportunidade de se deslocar à Coreia do Sul e falar com dissidentes norte-coreanos, o autor aceitou o repto. Assim, em 2013 iniciou a primeira de várias viagens como guia de grupos de cerca de 25 pessoas pelo território coreano, contrariando a convicção, expressa no final da narrativa, de que não voltaria ao país. Integrada num conjunto de itinerários com a designação de "Viagens com autores", esta proposta" constituiu o segundo circuito oferecido pela empresa para um público diferenciado, com a companhia de diversos especialistas, incluindo atualmente dois escritores - José Luís Peixoto e Raquel Ochoa - e um viajante-escritor - Gonçalo Cadilhe. ${ }^{12}$

É, assim, particularmente interessante a ocorrência de turismo literário num espaço tão fechado como a Coreia do Norte e sobretudo nos moldes em que foi desenvolvido: um circuito que partiu de uma experiência de viagem, que foi plasmada numa narrativa de viagens e cujo autor se converte no guia de outros visitantes.

\section{Representações do outro - entre o real e o simulacro}

Dentro do Segredo inicia-se no fim da viagem, à saída da Coreia do Norte, na "estação deserta de Sinuiji” (Peixoto, 2012: 10) onde os guardas da alfândega fiscalizam o passaporte e a

\footnotetext{
${ }^{11}$ De acordo com informação gentilmente cedida pela Pinto Lopes Viagens, José Luís Peixoto fez cinco viagens à Coreia do Norte como guia, entre setembro de 2013 e setembro de 2017. Inicialmente designado do mesmo modo que o livro - Dentro do Segredo - presentemente o circuito (que sofreu algumas alterações) ostenta o nome de "O mistério para lá do paralelo 38 - Coreia do Norte e Coreia do Sul", tendo saído do catálogo de "Viagens com autores". José Luís Peixoto mantém, porém, a colaboração com a empresa, na sequência da publicação do seu segundo livro de viagens, O Caminho Imperfeito (2017), fazendo agora circuitos na Tailândia.

${ }^{12}$ No site da empresa (https://www.pintolopesviagens.com/viagens-com-autores/), destaca-se o caráter inovador da oferta, que pretende diferenciar-se no panorama das viagens organizadas e do turismo massificado, pela acentuação da vertente cultural e literária, assim como se explicita que o autor não é um guia, mas alguém que partilha conhecimento e recebe o retorno do seu público: "Os autores (...), a partir de um conhecimento prévio e fundamentado do destino, criaram o conceito, a estrutura, o itinerário, as visitas e as opções de alojamento desta viagem. Sendo este projecto da sua autoria, os autores não se limitam a assiná-lo, claro. Estarão presentes ao longo de toda a viagem certificando-se que tudo corre como planearam. Por fim, a sua presença não é apenas reguladora: é pró-activa. Para um autor, esta é uma oportunidade única e irrepetível de contactar o seu público, de lhe explicar os seus pontos de vista, a sua perspectiva original sobre um destino em particular e sobre a vida em geral. É uma partilha."
} 
câmara fotográfica de José Luís Peixoto, dentro da carruagem do comboio. O resultado da inspeção às fotografias - algumas delas proibidas - fica em suspenso toda a narrativa, que se desenvolve numa longa analepse desde um ano antes, em Los Angeles, até aos intensos quinze dias que tinha durado a excursão então finalizada. E será, assim, apenas nas páginas finais que o leitor pode respirar de alívio, ao saber que a máquina é devolvida com "um olhar limpo" (Peixoto, 2012: 231) e que o autor pode prosseguir para a desejada liberdade em território chinês, onde recupera o telemóvel e volta a sentir os pequenos prazeres de comer o que lhe apetece e deambular sem o peso de ser vigiado.

Não será por acaso que o tempo da história se une precisamente nessa linha de fronteira vigiada ao extremo, onde as certezas se tornam precárias e o medo se faz anunciar. À saída do país, o tempo psicológico amplia-se e entra numa espécie de suspensão, pois é esse o momento mais crítico da viagem e é como tal que o viajante o representa - "eu sabia que se um fiscal quer encontrar algo com que implicar, não precisa de procurar muito e encontra sempre. É assim em qualquer parte do mundo. Quem fiscaliza tem demasiado poder nos olhos. Se disser que viu, ninguém pode contradizê-lo. Esse receio, ali, era multiplicado por um número desconhecido. Eu estava na Coreia do Norte" (Peixoto, 2012: 16).

Salman Rushdie, ainda que se refira a uma realidade simétrica - o não ocidental que tenta entrar na fortaleza norte-americana - chama precisamente a atenção para a fronteira como lugar de exclusão:

The frontier is a wake-up call. At the frontier we can't avoid the truth; the comforting layers of the quotidian, which insulate us against the world's harsher realities, are stripped away, and, wide-eyed in the harsh fluorescent light of the frontier's windowless halls, we see things as they are. [...] At the frontier our liberty is stripped away-we hope temporarily —and we enter the universe of control. [...] Here, at the edge, we submit to scrutiny, to inspection, to judgment. These people, guarding these lines, must tell us who we are. We must be passive, docile. To be otherwise is to be suspect, and at the frontier to come under suspicion is the worst of all possible crimes. (Rushdie, 2002: 79)

É uma das primeiras ironias da obra (e também a antítese do turismo tal como o conhecemos): a colocação do sujeito ocidental numa posição de fragilidade perante o desconhecido, o outro que tem o poder de decidir a admissão na sua própria fortaleza. E ao mesmo tempo, acaba por ser também uma primeira declaração de humildade, a submissão voluntária a uma despossessão simultaneamente material (a tecnologia que fica do lado de cá) e existencial (nada será semelhante à realidade conhecida).

A segunda ironia, se assim podemos chamar, emerge também nestas páginas iniciais, aliás, desde a epígrafe: a relação intertextual, qual jogo de espelhos, com a obra Dom Quixote de Cervantes, carregada clandestinamente para a Coreia do Norte. Como o cavaleiro castelhano, o autor-viajante sente a dualidade entre o real e o simulacro; as imagens captadas pelos sentidos não são inteiramente fiáveis e é necessário - mas frequentemente impossível - destrinçar o que é verdade e o que é simulação:

Com frequência, senti que apenas me restava o papel de testemunha alucinada, tentando distinguir a realidade real da realidade retórica apenas através do instinto. Não foi por acaso que escolhi reler D. Quixote na Coreia do Norte.

Como ele, basta-me ser fiel à verdade que conheço e em que acredito. Na vida, talvez seja sempre assim. A sinceridade salva-nos perante nós próprios. (Peixoto, 2012: 62-63) 
A tensão entre o real e o simulacro perpassa toda a obra e são numerosos os exemplos em que o turista-viajante é levado a duvidar daquilo que é posto perante os seus olhos. Seja na fábrica de fertilizantes, onde não há sinais de laboração que pudesse produzir as anunciadas setecentas mil toneladas de fertilizante (idem: 173-175); seja no suposto laboratório de química, onde uma mulher misturava um pó branco num frasco com água (idem: 145-146); seja na casa dos trabalhadores da cooperativa agrícola sem sinais de ser habitada (idem: 181182), tudo parece encenado e fingido, para que os turistas pudessem construir uma representação positiva de um país inexistente.

Nos locais mais associados à fruição turística - hotéis, restaurantes, espaços de lazer, centros comerciais - o desconcerto persiste e assume uma nova forma: tudo parece idêntico ao turismo ocidental de massas, mas nada (ou quase nada) o é. Desde os banhos de lama decrépitos que nem remotamente se assemelham a uma experiência de spa ao restaurante de hambúrgueres deserto e antiquado onde os únicos clientes eram os doze turistas do grupo ou às lojas (a n. $\left.{ }^{\circ} 1 \mathrm{a} \mathrm{n.}^{\circ} 2\right)$ igualmente vazias de clientes locais, observa-se uma modernidade fingida que simula os estereótipos da indústria turística.

O turismo contemporâneo tem sido frequentemente associado à ideia de simulacro, decorrente da mercantilização da indústria turística, que propõe como "autêntico" aquilo que, na realidade, é fabricado em função de critérios mercantilistas. O turista, ao contrário do viajante, contenta-se com a encenação do autêntico; contudo, a busca da autenticidade é algo permanentemente presente nos discursos publicitários. Como afirma Culler (1981: 129), a distinção entre o autêntico e o inautêntico, o natural e o turístico, é um poderoso operador semântico dentro do turismo. Deste modo, a autenticidade é em si mesma um paradoxo: "The authenticity the tourist seeks may seem at one level to be an escape from a code, but the authentic is always marked, requires a mark to be constituted as authentic, and nothing is more coded than the cliched versions of authentic travel experiences." (Culler, 1981: 132).

$\mathrm{Na}$ Coreia da Norte, como temos observado, a diferença entre o autêntico e o simulacro é sempre precária, cai numa margem de indeterminação que depende da subjetividade de quem o vê - ou, no caso presente, de quem o narra. Na sua qualidade de guias, o senhor Kim e a menina Kim seriam, no Ocidente, os porta-vozes de uma experiência turística que mostra aos clientes o que se acredita que eles querem ver - não propriamente o autêntico, mas o que os turistas percecionam como a experiência genuína do local. Neste contexto, porém, como funcionários do Estado e não de uma indústria privada lucrativa, eles e todos os outros guias estão vinculados a uma leitura ideológica de sentido único que transmitem como autêntica porque para eles é, de facto, a única possível. A dúvida e o ceticismo está do lado de quem escuta, pois como turistas diferenciados de um destino incomum, José Luís Peixoto e os companheiros de viagem não vieram à procura da experiência cliché a que se referia Culler.

O hotel Yanggadko, onde os estrangeiros ficam alojados, ilustra bem esta duplicidade: simula um hotel de luxo, com os seus mil quartos, quarenta e sete andares, restaurante giratório, bowling, karaoke, casino, cabeleireira - contudo, é apenas, ao olhar ocidental, um hotel antiquado cujo luxo maior é a existência de água corrente na casa de banho e um telefone para chamadas internacionais. Todos os outros hotéis onde ficam, no norte, não têm sequer água corrente no quarto - a realidade torna-se aí mais nua, o turismo tão ilusório quanto o resort abandonado, construído pelos sul coreanos da Hyundai e que teve de ser 
encerrado após a morte de uma turista por militares (embora a versão oficial, naturalmente, dê como culpada a Coreia do Sul).

\section{Notas conclusivas}

Se estás a ler estas palavras é porque estás vivo.

(Peixoto, 2012: 236)

Ainda que a literatura de viagens tenha um papel secundário na produção do espaço turístico, é importante para a forma como os mesmos são imaginados (Robinson, 2004: 331). Num território tão fortemente condicionado como a Coreia do Norte, os relatos de viagem lançam alguma luz - necessariamente subjetiva - sobre uma realidade que é elusiva mesmo para quem testemunha, de corpo presente, os espaços e a população. O que fica de Dentro do Segredo. Uma viagem na Coreia do Norte é, assim, um manifesto de procura não da verdade, mas da viagem em si mesma, seguindo a lição de Lao Tsé, citado nas últimas frases da narrativa: “Um bom viajante não tem planos fixos nem a intenção de chegar" (Peixoto, 2012: 236).

Para José Luís Peixoto, o turismo na Coreia do Norte, que o seu livro, traduzido em várias línguas, também ajuda a impulsionar, parece enquadrar-se no turismo moral a que Connell se referia - a normalização possível do outro, através da superação da negatividade associada às imagens construídas no Ocidente. O seu objetivo, tanto na escrita e publicação da obra, como na atividade de guia que posteriormente desenvolveu, comporta assim um sentido ético:
Pessoalmente, como muitos, acredito que o turismo pode ser uma forma de contribuir para uma abertura e, por consequência, para uma mudança importante na sociedade norte-coreana. [... ] Trata-se de toda uma população que ignora estrangeiros, que nunca teve contacto com quase nada do que damos por adquirido. Os norte coreanos reparam naquilo que já deixámos de ver. [... ] É fácil ficar em casa, cultivar a queixa ou o sarcasmo. Difícil é ir lá. Um dia, quando nos chegarem notícias de mudança, saberemos que essa história também é nossa e, mesmo que apenas com um grão de pó, com um grama, contribuímos para a libertação daquele povo. (Peixoto, 2015)

Longe de ser consensual (os dissidentes, em particular, consideram que é uma forma de perpetuar o regime e uma aceitação tácita da manipulação ideológica), o turismo na Coreia do Norte tem crescido a uma velocidade imparável e, apesar de todos os constrangimentos, é expectável que as estruturas turísticas acompanhem a evolução. Entre o real e o simulacro sobra, pois, uma grande margem de indeterminação onde é ao viajante - o que viaja com o corpo ou o que viaja com as letras - que cabe desenhar a sua presença e deixar a sua marca.

A par do aumento de turistas, o aparecimento de um número cada vez mais significativo de narrativas de viagens centradas na Coreia do Norte revela bem o interesse que este país, apesar ou por causa do seu fechamento, provoca no Ocidente, porventura por ser ainda, juntamente com um pequeno punhado de outros territórios, o domínio do inalcançável e do proibido. E se na presente reflexão apenas pudemos referir-nos a um texto, cujo pendor literário é inequívoco, consideramos de grande pertinência uma abordagem comparativa que 
ponha em confronto outras vozes e outras perspetivas. Deste modo se poderão abrir caminhos para um entendimento descentrado do turismo literário e do turismo na literatura, pela análise de uma realidade que escapa a todos os lugares comuns e desafia os pressupostos sobre os quais construímos a nossa visão do mundo lá fora.

\section{Referências}

Blanton, C. (2002). Travel writing: The self and the world. Londres: Routledge.

Buda, D. M. \& Shim, D. v (2015). Desiring the dark: 'A taste for the unusual' in North Korean tourism? Current Issues in Tourism, 18(1), 1-6. doi: 10.1080/13683500.2014.948813

Connell, J. (2017). Shining light on the darkness. Placing tourists within North Korean tourism. Comment on: 'Desiring the dark: a taste for the unusual?' in North Korean tourism? Current Issues in Tourism, 20(4), 356-362, doi 10.1080/13683500.2015.1032896

Culler, J. (1981). Semiotics of tourism. The American Journal of Semiotics, 1(1/2), 127-140. doi: 10.5840/ajs198111/25

Giuliani, F. (2018). Corea del nord: Viaggio nel paese-bunker. Florença: Mauro Pagliai Editore.

Grangereau, P. (2000). Au pays du grand mensonge: Voyage en Corée du Nord. Paris: Petite Bibliothèque Payot / Voyageurs.

Grieco, F. (2018). En Corea del Norte: Viaje a la última dinastía comunista. Barcelona: Debate.

Harris, S. (2019). Traveling through North Korea: Adventures in the Hermit Kingdom. Big Beaver Diaries. JaBone, J. R. (2019). Rocketbone's guide to North Korea [Edição do autor].

Martínez Pitarch, B. (2012). Cerrado 24 horas: Crónica de un viaje a Corea del Norte. Barcelona: Laertes. Medlik, S. (2003). Dictionary of travel, tourism and hospitality. Londres e Nova lorque: Routledge.

Palin, M. (2019). North Korea Journal. London: Hutchinson.

Peixoto, J. L. (2012). Dentro do segredo. Uma viagem na Coreia do Norte. Lisboa: Quetzal.

Peixoto, J. L. (2015). José Luís Peixoto leva-nos ao dia-a-dia da Coreia do Norte. [Entrevista de Nuno Mota] Volta ao Mundo, maio, n. ${ }^{\circ}$ 247. Disponivel em https://www.voltaaomundo.pt/2018/08/12/escritor-jose-luis-peixoto-coreia-do-norte-como-ea-vida-num-dos-paises-mais-fechados-do-mundo-a/destinos/317/

Pinto Lopes Viagens. Viagens com Autores. Disponível em https://www.pintolopesviagens.com/viagens-com-autores/

Prentice, R. (2004). Tourism motivations and typologies. In A. Lew, C. M. Hall \& A. M. Williams (Eds.), A companion to tourism (pp. 261-279). Malden/Oxford/Victoria: Blackwell Publishing.

Quinteiro, S. \& Baleiro, R. (2017). Estudos em literatura e turismo. Conceitos fundamentais. Lisboa: Universidade de Lisboa, Faculdade de Letras, Centro de Estudos Comparatistas.

Rego, V. (2017). O invisível Hotel Ryugyong, representações do Outro no romance Dentro do segredo, uma viagem na Coreia do Norte, de José Luís Peixoto. In Atas do V SIMELP - Simpósio Mundial de Estudos de Língua Portuguesa (pp. 1409-1432). Lecce: Itália. doi 10.1285/i9788883051272

Righetti, N. (2003). Le dernier paradis: Voyage en Corée du Nord. Geneva: Editions Olizane.

Robinson, M. (2004). Narratives of being elsewhere: Tourism and travel writing. In A. Lew, C. M. Hall \& A. M. Williams (Eds.), A companion to tourism (pp. 303-315). Malden/Oxford/Victoria: Blackwell Publishing.

Rushdie, S. (2002). Step across this line. The Tanner lectures on human values. Disponível em https://tannerlectures.utah.edu/_documents/a-to-z/r/rushdie_2002.pdf.

Simmons, W. E. (2015). My holiday in North Korea: The funniest/worst place on earth. Nova lorque: Rosetta Books. 


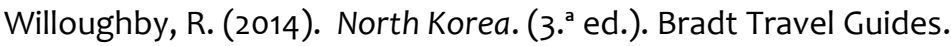

Ana Margarida Fonseca é professora adjunta no Instituto Politécnico da Guarda. Possui mestrado e doutoramento em Literatura Comparada pela Faculdade de Letras da Universidade de Lisboa. Membro integrado do Instituto de Literatura Comparada Margarida Losa (FLUP) e membro colaborador do Centro de Estudos Comparatistas (FLUL). Para além de publicações em revistas, obras coletivas e livros de atas de âmbito nacional e internacional, é autora de Projectos de Encostar Mundos. Referencialidade e Representação na Literatura Angolana e Moçambicana dos Anos 80 (Prémio Revelação da APE - Ensaio Literário, Difel, 2002) e de Percursos da Identidade. Representações da Nação na Literatura Pós-Colonial de Língua Portuguesa (Fundação Calouste Gulbenkian /FCT, 2012). Os principais interesses de investigação centram-se nas áreas dos estudos pós-coloniais, estudos de identidade e ficção contemporânea em língua portuguesa (Portugal, Angola e Moçambique). Endereço institucional: Línguas e Culturas, Escola Superior de Educação, Comunicação e Desporto, Instituto Politécnico da Guarda, Guarda, 6300-559, Portugal.

Submetido em 22 de abril de 2020

Aceite em 23 de junho de 2020 